\title{
MINISTÉRIO PÚBLICO, LAVA JATO E MÃOS LIMPAS: UMA ABORDAGEM INSTITUCIONAL
}

\section{Fábio Kerche}

é doutor em Ciência Política pela Universidade de São Paulo (USP). São Paulo, São Paulo, Brasil. Também é pesquisador titular da Fundação Casa de Rui Barbosa. Rio de Janeiro, Rio de Janeiro, Brasil.E-mail:<fabio.kerche@rb.gov.br> Orcid: https://orcid.org/0000-0002-0503-6446 http://dx.doi.org/10.1590/0102-255286/105

\section{Introdução}

Em fevereiro de 1992, na cidade italiana de Milão, um administrador de um hospital público, membro pouco expressivo do Partido Socialista, foi pego recebendo US\$5.000,00 em propina. A partir desse caso, a “Operação Mãos Limpas" foi deflagrada pelo sistema judicial da Itália e as consequências nos anos seguintes superlativas: 5.000 pessoas envolvidas nas investigações (Guarnieri, 2015), entre elas seis ex-primeiros-ministros e 200 parlamentares (Sberna e Vannucci, 2013). Como reflexo das operações de combate à corrupção, o sistema partidário sofreu mudanças dramáticas e o antigo equilíbrio político construído no pós-guerra se desmanchou (Pederzoli e Guarnieri, 1997). Entre 1992 e 1994, os cinco partidos políticos mais importantes “colapsaram de 53,1\% para 13,8\%. Democratas Cristãos renomeados como Partido Popular - caíram de 29,6\% para 11,1\%; o Partido Socialista de 13,6\% para 2,2\%" (Pederzoli e Guarnieri, 1997, p. 326, tradução nossa). Mesmo as agremiações que não participavam das coalizões que governavam a Itália após a Segunda Grande Guerra, como o Partido 
Comunista e os grupos pós-fascistas, sofreram transformações radicais nos anos seguintes (Sberna e Vannucci, 2013). Enquanto isso, "novos atores políticos emergiram na cena para preencher o vácuo político que foi deixado pela desintegração do velho" (Sberna e Vannucci, 2013, p. 575, tradução nossa). É nesse contexto que Silvio Berlusconi, o homem mais rico da Itália, proprietário de vários veículos de comunicação e neófito na política, cria um novo partido de centro-direita, Forza Italia, e se torna primeiro-ministro do país (Sberna e Vannucci, 2013).

Anos após esses acontecimentos na Itália, em março de 2014, no Brasil, o Ministério Público Federal deflagra uma operação que ganhou nos anos subsequentes proporções inéditas no combate à corrupção. A "Operação Lava Jato", assim chamada porque envolvia o "uso de uma rede de postos de combustíveis e lava a jato de automóveis para movimentar recursos ilícitos pertencentes a uma das orga256 nizações criminosas inicialmente investigadas" ", foi o ponto de partida que passou pela Petrobras, grandes empreiteiras e partidos políticos. Os números são expressivos para os padrões brasileiros: 1.434 procedimentos instaurados, 730 buscas e apreensões, 197 prisões preventivas, 103 prisões temporárias, seis prisões em flagrante, 71 acordos de colaboração premiada e nove acordos de leniência com empresas $^{2}$. Entre os presos, importantes políticos e grandes empresários. Empresas brasileiras com projetos inclusive no exterior sofreram expressivas perdas financeiras e de imagem após a deflagração da Operação ${ }^{3}$. O processo de impeachment da presidente Dilma Rousseff, embora não

1 Disponível em: <http:/ / lavajato.mpf.mp.br/entenda-o-caso >. Acesso em: 14 fev. 2017.

2 Disponível em: <http://lavajato.mpf.mp.br/entenda-o-caso $>$. Acesso em: 14 fev. 2017.

3 Disponível em: <http://www.bbc.com/portuguese/noticias/2015/12/151201_ lavajato_ru>. Acesso em: 14 fev. 2017. 
tenha sido formalmente baseado em corrupção, foi alimentado pelas denúncias e prisões. O Partido dos Trabalhadores viu seu apoio popular cair ${ }^{4}$ e teve uma expressiva perda do número de prefeituras administradas pela legenda nas eleições de 2016, possivelmente em parte por conta do desgaste sofrido pela criminalização de seus membros. Foram 638 prefeituras conquistadas em 2012 e apenas 254 em 2016, sendo somente uma capital de estado, Rio Branco (AC) ${ }^{5}$. A Operação Lava Jato, mesmo que todas as suas consequências não sejam mensuráveis, já deixou marcas profundas na economia e na política brasileira.

Um dos principais protagonistas da Operação Lava Jato, o juiz federal de primeira instância Sérgio Moro, escreveu sobre a operação italiana. Em artigo, afirma que a Operação Mãos Limpas é um "momento extraordinário na história contemporânea do Judiciário" e "constitui objeto de estudo obrigatório para se compreender a corrupção nas democracias contemporâneas e as possibilidades e limites da ação judiciária em relação a ela" (Moro, 2004, p. 57). O combate à corrupção pela via judicial da Itália, inegavelmente, é fonte de inspiração para o sistema judicial brasileiro.

A pergunta, contudo, é se a experiência italiana foi reproduzida de alguma forma no Brasil para além da inspiração. Dito de outra maneira, as similaridades se restringem somente ao desejo, e ao fato, de que promotores e um juiz de instância inicial utilizem a via judicial e as ações penais para "purificar" a política ou há outras semelhanças? Do ponto de vista institucional, o que aproxima os integrantes da Lava Jato e os magistrados italianos que conduziram a Operação Mãos Limpas?

\footnotetext{
${ }^{4}$ Disponível em: <http://infograficos.oglobo.globo.com/brasil/partido-do-voce-nao-me-representa.html>. Acesso em: 14 fev. 2017.

${ }_{5}^{5}$ Disponível em: <http://www.bbc.com/portuguese/brasil-37710397>. Acesso em: 14 fev. 2017.
} 
A comparação institucional envolve sempre algum risco. Ao aproximar excessivamente a "lupa", pode-se chegar à conclusão de que os modelos são tão diversos que não existem semelhanças. Ao afastá-la em excesso, corre-se o risco de afirmar que as instituições são iguais, porque perde-se a dimensão dos detalhes. Essa dificuldade se agrava quando a literatura trata o sistema de justiça italiano como um modelo único entre as democracias consolidadas (Di Federico, 1995). Ou seja, sendo singular, as semelhanças entre as operações de combate à corrupção no Brasil e na Itália conduzidas por promotores $^{6}$ e juízes, por esse raciocínio, seriam restritas ao ponto da motivação, mas não do ponto de vista da organização institucional.

Há importantes diferenças entre os sistemas judiciais italiano e brasileiro, além do sistema político como um todo. A diferença mais marcante para os objetivos deste estudo é que o conceito de "foro especial" (ou "foro pri258 vilegiado", como é recorrentemente chamado no debate público), não existe na Itália com a amplitude encontrada no Brasil. No país europeu, somente o presidente da república é julgado pela Corte Constitucional, sendo que todos os outros políticos "submetem-se à jurisdição ordinária, após autorização do Senado da República ou da Câmara dos Deputados, conforme as normas estabelecidas pela lei constitucional (art. 96)" (Tavares Filho, 2016, p. 10). Nesse sentido, na Itália, quase todos os políticos, incluindo aqueles com assento no gabinete ou no parlamento, são passíveis de serem investigados e julgados pelas instâncias inferiores da justiça. No Brasil, o presidente da república, seus ministros e parlamentares somente podem ser acusados pelo procurador-geral da república e julgados pelo Supremo Tribunal Federal (STF). Esta particularidade do

\footnotetext{
${ }^{6}$ Vou tratar por "promotor" todos os integrantes de instituições responsáveis pela ação penal no Brasil e em outras democracias, a despeito de diferentes denominações que este possam receber ao longo da carreira ou do vínculo institucional.
} 
modelo institucional e suas consequências, que impacta no cálculo dos políticos denunciados, não serão tratadas neste momento. Buscarei demonstrar, contudo, que a Lava Jato, no seu núcleo de primeira instância, foi facilitada porque o modelo judicial brasileiro, que já era próximo do italiano, aproximou-se ainda mais do desenho do país europeu. Por meio de leis e acordos tácitos entre os agentes judiciais, investigar e processar políticos sem cargo ou mandato e empresários foi facilitado na instância inferior. A Operação Mãos Limpas foi mais que simplesmente a inspiradora dos juízes e promotores da Lava Jato em primeira instância: na verdade, a operação só pôde ganhar grandes dimensões quando aproximou-se ainda mais, do ponto de vista institucional, do modelo italiano.

Essa aproximação foi construída a partir da Constituição brasileira de 1988 e reforçada por mudanças ocorridas nos últimos anos, ora fruto de novidades institucionais criadas pelos políticos e pelo STF durante os governos petistas de Lula da Silva (2003-2010) e Dilma Rousseff (2011-2016), ora por acordos tácitos entre os próprios policiais, promotores e, aparentemente, o juiz do caso. Houve, como será demonstrado neste artigo, uma espécie de "italianização" do ponto de vista institucional e de estratégia de judicialização do combate à corrupção em instância ordinária que, assim como na Itália, gerou impacto na política do país.

Teremos como fio condutor para a construção do argumento o modelo institucional das agências responsáveis pela ação penal, chamadas de Ministério Público (MP) no Brasil e na Itália. São os atores ligados ao MP a chave para entender as particularidades do modelo, aproximando os dois sistemas e diferenciando-os de outras democracias.

O artigo, além desta introdução, será dividido em quatro partes: a primeira apresenta uma classificação das agências responsáveis pela ação penal nas democracias; a 
segunda descreve o modelo da justiça italiana e suas estratégias na Operação Mão Limpas; a terceira mostra como o modelo do sistema de justiça brasileiro de primeira instância se aproximou do italiano e as consequências disso para a Operação Lava Jato e, finalmente, apresento uma pequena conclusão.

\section{Os promotores nas democracias}

Todos os Estados com democracias consolidadas possuem uma instituição responsável pela ação penal. Se o monopólio da violência é do Estado cabe a um ator estatal, o promotor, exigir que aquele que lançou mão da violência de maneira ilegítima seja punido (Weber, 1972).

Se o fato dos Estados possuírem uma organização responsável pela ação penal é um aspecto comum às democracias, as características dessas instituições são diversas entre si. Elas variam no que diz respeito à localização na 260 estrutura estatal (parte do Poder Executivo, Judiciário ou independente); características do sistema legal e como se dá a seleção, recrutamento e treinamento dos promotores (Tonry, 2012).

As variáveis políticas mais importantes, contudo, e que podem ser estendidas a todos os atores estatais, são a accountability e a discricionariedade (Przeworski,1998b; Lotta e Santiago, 2017). Observar qual outra instituição ou agente detém instrumentos para responsabilizar um ator político por seus atos e escolhas e qual o grau de liberdade desse ator para tomar decisões são aspectos fundamentais para a compreensão do papel das organizações estatais na democracia, incluindo aquelas que abrigam os promotores. Explico:

I) Accountability: na democracia, os atores prestam contas de seus atos e escolhas e respondem por isso a um ator externo, podendo ser punidos ou premiados por sua 
atuação. $\mathrm{O}$ ator externo é alguém ou uma agência com independência e sem laços institucionais com aquele que é fiscalizado ${ }^{7}$. Embora haja vários tipos de accountability (Bovens, Goodin e Schillemans, 2014), é possível agrupálos em dois tipos (O’Donnell, 1998). A vertical é aquela exercida pelos eleitores nas eleições que, de forma regular e direta, punem ou premiam os políticos por suas escolhas e ações. Isso serve de incentivo para que os políticos, que continuarão disputando eleições, não percam de vista os interesses de seus eleitores quando tomarem suas decisões, optarem por certas políticas públicas e orientarem a burocracia. A horizontal, por sua vez, é aquela exercida por agências e atores estatais em relação a outras agências e atores na estrutura do Estado. Elas podem ser categorizadas em dois grandes tipos: a exercida pelo Poder Judiciário ${ }^{8}$ e a exercida por políticos e por agências estatais. Baseado nesta tipologia, existem quatro combinações possíveis, em ordem decrescente, que serão distribuídas no eixo da accountability da figura 1: i) um ator ser accountable verticalmente e horizontalmente; ii) um ator ser accountable horizontalmente por outras agências e pelo Judiciário; iii) um ator ser accountable pelo Judiciário e iv) um ator não ser accountable.

II) Discricionariedade: os atores estatais detêm graus diversos sobre o que podem deliberar e qual o grau de liberdade para fazê-lo. Portanto, discricionariedade envolve um "espaço para escolhas legais garantido formalmente" ou "algum grau de arbitrariedade (...)

\footnotetext{
7 Por este critério, uma corregedoria não seria um instrumento de accountability, por exemplo.

8 A accountablity exercida pelos juízes, que são bastante protegidos da accountability de outros atores, é assunto controverso na Ciência Política. Não irei me debruçar sobre esse debate neste momento. Para os efeitos deste artigo, assumo que a accountability judicial tem a mesma importância das outras formas de accountability.
} 
dentro dos limites legais de sua atuação" (Lotta e Santiago, 2018, p. 23-24). Um político pode decidir de forma livre sobre uma gama expressiva de assuntos, escolhendo, segundo seus próprios critérios, qual a política que deve ser adotada. Um funcionário do departamento de trânsito no Rio de Janeiro, por exemplo, tem como papel somente verificar de forma quase automática se um automóvel está dentro dos padrões prédeterminados, tendo pouca liberdade para decidir algo que já não esteja previsto na legislação. Nesse sentido, a discricionariedade do político é maior do que do agente de trânsito. Essa maior ou menor discricionariedade é representada no eixo correspondente da figura 1.

Do ponto de vista normativo, o político, que pode decidir com liberdade sobre uma gama expressiva de assuntos, precisa ser mais accountable que um "burocrata de nível de 262 rua" com menor liberdade de escolha. Criar uma estrutura complexa de accountability para alguém que simplesmente deve aplicar a lei definida em parâmetros claros e inequívocos seria um desperdício de energia e recursos públicos. Portanto, na democracia, quanto maior a discricionariedade, maior deveria ser a accountability.

O desenho institucional das agências responsáveis pela ação penal nas democracias tradicionais, normalmente, se baseia nesse princípio. A discricionariedade tem relação com a accountability. A figura 1 sintetiza os quatro tipos possíveis de promotoria nas democracias baseada nessas duas variáveis ${ }^{9}$. No "modelo eleitoral", os promotores têm alta discricionariedade, mas são

\footnotetext{
${ }^{9}$ Em análise anterior, as agências responsáveis pela ação penal foram classificadas em "promotores ligados ao ministro da Justiça" e "promotores independentes" (Kerche, 2009). Com novas informações e mais pesquisas, creio que a classificação em "Burocrática", "Eleitoral" e "Independente/Autônoma" explicite melhor as diferenças entre os modelos.
} 
altamente accountable, tanto do ponto de vista vertical (por meio de eleições), quanto dos dois tipos de horizontal (outras agências estatais e Poder Judiciário). No "modelo burocrático", a discricionariedade dos promotores é intermediária e a accountability é restrita à horizontal (exercida por outras agências e pelo Poder Judiciário). Como é possível identificar combinações diversas entre accountability e discricionariedade, é apropriado marcar uma área e não apenas um ponto específico na figura 1. O "modelo independente/autônomo" é aquele em que os promotores praticamente não respondem a atores externos. Para destacar as particularidades entre o modelo brasileiro e italiano, vou chamar o primeiro de autônomo e o segundo de independente, embora os termos sejam intercambiáveis (Dahl, 1982). O modelo autônomo é o previsto na Constituição brasileira de 1988, em que a discricionariedade e a accountability são baixas. O promotor, como será detalhado, detém pouca liberdade de escolha em relação às ações penais e é accountable basicamente ao Poder Judiciário. A Itália com seu "modelo independente" se encontra na área em que a discricionariedade é alta e a accountability, baixa. Como os juízes e promotores fazem parte do mesmo poder, o princípio de que accountability é exercida por um ator externo se enfraquece. Irei demonstrar que no caso brasileiro, especialmente durante a Operação Lava Jato, o MP se aproximou do modelo italiano, com mais discricionariedade e com as barreiras entre Poder Judiciário e MP mais tênues. 
Figura 1

Promotores, Accountability e Discricionariedade

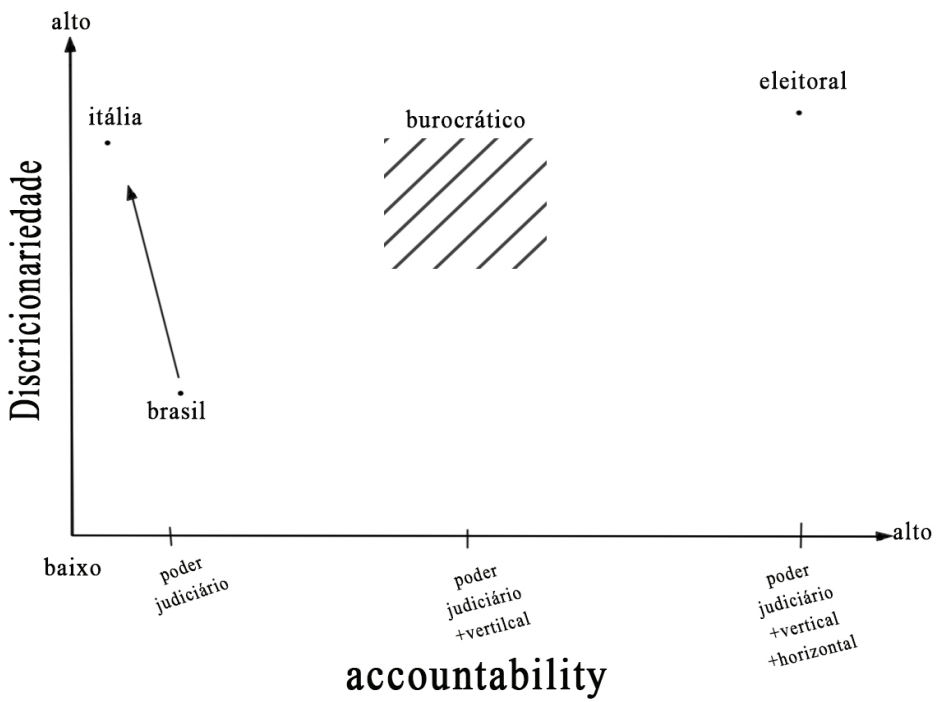

Fonte: Elaboração própria

\section{Modelo burocrático}

As agências responsáveis pela ação penal são normalmente um órgão do Poder Executivo em países democráticos, mesmo ocorrendo variações em relação à discricionariedade e à accountability. De qualquer forma, é o governo, e não um particular ou o Poder Judiciário, que é encarregado de processar o cidadão que cometeu um crime e de determinar a política criminal do país. O papel de exigir o correto cumprimento da lei é realizado com a colaboração dos promotores subordinados ao ministro da justiça. É o ministro que fiscaliza a atuação dos promotores, escolhe prioridades, acompanha a execução do orçamento etc. E é o governo, em última instância, que é accountable junto ao cidadão pela atuação da promotoria, aproximando-os de um modelo típico de qualquer outra burocracia. Pela 
característica de envolver prioridades e alocação de recursos, já que não é possível processar todos os crimes, a promotoria "é uma função executiva, não judicial" (Shapiro, 2013, p. 262, tradução nossa). Esse é o modelo em países tão diversos do ponto de vista do sistema político, como Estados Unidos em nível federal, Espanha, França e Inglaterra, assim como Alemanha, Holanda e Japão, que na prática respondem ao Poder executivo, embora formalmente façam parte do Judiciário (Fionda, 1995; Kerche, 2009; Johnson, 2012).

Como o Poder Judiciário normalmente é inerte e age somente quando provocado por um terceiro, o papel de controlar o fluxo de ações penais propostas aos juízes é fundamental. São os promotores, exercendo o papel de gatekeepers do sistema de justiça (Aaken, Feld e Voigt, 2010), que fazem o primeiro filtro do que deve ou não ser levado à decisão do Judiciário, “(...) permitindo ao ambiente político regular até certo ponto as demandas por ações colocadas ao sistema judicial" (Guarnieri, 1995, p. 244, tradução nossa). Dito de outra forma, como o Judiciário geralmente é o Poder menos accountable, inclusive porque suas decisões não deveriam se basear na vontade da maioria, um ator accountable selecionar o que vai ser decidido pelos autônomos juízes permite certo grau de controle popular sobre o sistema.

$\mathrm{O}$ direito de selecionar o que será discutido no âmbito penal é, portanto, extremamente importante. "Geralmente as mais importantes decisões discricionárias são as negativas, como não iniciar, não investigar, não processar, não entrar em acordo, e as decisões negativas geralmente significam uma disposição definitiva" (West, 1995, p. 25, tradução nossa). No modelo burocrático de promotoria, contudo, o governo pode ser responsabilizado pelos eleitores inclusive por decisões discricionárias negativas tomadas pelos promotores. Quando os políticos delegam aos promotores o direito de fazer certas escolhas, a contrapartida é que esses promotores devem responder ao governo. Quando os 
cidadãos delegam aos políticos o direito de fazer certas escolhas, inclusive na área criminal, a contrapartida é que esses cidadãos podem punir os políticos, ou premiá-los, por meio das eleições ${ }^{10}$. A desvantagem, entretanto, é que a ligação com o governo diminui a autonomia do promotor para processar os políticos.

\section{Modelo eleitoral}

O modelo eleitoral seleciona seus promotores por meio de eleições diretas e regulares, em um processo semelhante à disputa de qualquer outro cargo público, sofrendo dos mesmos incentivos e restrições de outros políticos. $\mathrm{O}$ modelo é encontrado na maior parte dos Estados Unidos: no nível dos condados a escolha é para os district attorney (DA), e em nível estadual, para attorney-general dos estados, que não exercem poder hierárquico em relação aos DA. Assim, "o sistema de eleições para promotores fornece de 266 forma contínua altos incentivos para a mídia e potenciais partidos ou indivíduos rivais monitorar como os processos são conduzidos" (Shapiro, 2013, p. 261, tradução nossa). Não é por outra razão que são os promotores que tem maior grau de discricionariedade e com grande autonomia para negociar penas sem a participação do juiz. Este alto grau de discricionariedade é contrabalanceado por uma accountability vertical, exercida diretamente pelos cidadãos por meio de eleições regulares.

A accountability vertical estimula que os "promotores americanos, algumas vezes de forma aberta e sem constrangimento, levem em conta as reações da mídia, a opinião pública e razões políticas quando decidem que casos irão dar prosseguimento e como lidarão com eles" (Tonry, 2012, p. 2, tradução nossa). Em anos eleitorais, segundo pesquisas

10 "É precisamente esta responsabilidade política do ministro da justiça que permite manter a quase-irresponsabilidade civil dos magistrados para os fatos relevantes de suas funções" (Terquem, 1998, p. 131, tradução nossa). 
realizadas em diversos estados, os DA são mais punitivos, apresentam mais casos ao júri e dão preferência para os processos de maior repercussão do que nos anos sem eleições (Tonry, 2012). Se o modelo tem a vantagem da accountability direta por parte dos cidadãos, por outro lado, a utilização de critérios não judiciais é estimulada pela lógica da disputa eleitoral.

\section{Modelo autônomo e modelo independente}

Outros modelos são os de promotorias pouco accountable, em que o desenho institucional assegura altas doses de autonomia em relação aos políticos e, em última instância, aos cidadãos. Esse é o caso do Brasil e da Itália ${ }^{11}$. Embora existam diferenças institucionais importantes, em ambas, como veremos, os promotores são significativamente autônomos em relação ao governo, parlamento e outras agências estatais. As ingerências internas são dificultadas, já que a carreira de seus integrantes é relativamente protegida de processos hierárquicos. Os cidadãos, mesmo que por meio de seus representantes, detêm parcos instrumentos para incentivar determinados comportamentos dos promotores. Assim, quando “(...) por uma feliz coincidência, burocratas [leia-se promotores] agem como os cidadãos desejam que eles ajam; a burocracia pode parecer não ser um problema tão grande, mas não está sob controle democrático" (Gruber, 1987, p. 12, tradução nossa). Isso porque o

"Controle deveria ocorrer por meio de um processo de reações antecipadas. Se os burocratas antecipassem com precisão o que os cidadãos gostariam que fosse feito, e então se sentissem constrangidos a agir baseados nesta

11 Entre 1978 e 1999, existiu nos Estados Unidos um modelo de promotoria altamente insulada para casos que envolvessem o presidente da república e outras altas autoridades. O Independent Counsel foi extinto após debates que apontavam, entre outras coisas, que a falta de accountability representava um problema para a democracia norte-americana. (Johnson e Brickman, 2001; Burbank e Friedman, 2002). 
antecipação, uma forma de controle democrático teria ocorrido. Mas se os burocratas estiverem errados na sua antecipação e agirem em um sentido em que os cidadãos e o Legislativo não aprovem, não se pode dizer que suas ações foram controladas pelos cidadãos" (Gruber,1987, p. 12-13, tradução nossa).

O modelo italiano e brasileiro foi desenhado, pelo menos em teoria, para que os promotores tivessem pouca discricionariedade e baixa accountability, o que seria menos incomum em sistemas democráticos. No entanto, os integrantes de ambas instituições são, de facto (e de jure mais recentemente) atores discricionários. Como todas as escolhas institucionais, esta tem vantagens e desvantagens. Se, por um lado, os promotores são mais livres para processar políticos em casos de corrupção, por outro, a possibilidade

268 de responsabilização dos próprios promotores para além do Poder Judiciário é bastante dificultada, para não dizer impossível. O modelo, incomum para democracias, se baseia mais no "acaso" do que em regras e incentivos institucionais. Ao cidadão resta poucas alternativas além de torcer para que os objetivos dos promotores coincidam com os seus ${ }^{12}$.

\section{0 caso italiano}

A Itália promulgou sua constituição democrática em 1948, após o regime fascista. Em relação ao sistema de justiça, os constituintes mantiveram o modelo de um Poder Judiciário e MP unificados. Assim, um mesmo integrante do sistema de justiça, após entrar na instituição por meio de um concurso público, pode exercer ao longo de sua carreira ora o papel de juiz, ora o de promotor, a ponto de que “(...) o

\footnotetext{
12 Outra maneira de abordar a questão de incentivos aos promotores seria por meio do modelo agent/ principal. Para um exemplo disso (Kerche, 2009).
} 
público em geral não percebe mais a diferença entre os dois papéis" (Di Federico, 1995, p. 235, tradução nossa).

A novidade, que serviu como uma espécie de resposta ao período anterior - em que as promoções, indicações, remoções e decisões de quais casos processar eram tomadas pelo governo -, foi garantir altas doses de autonomia aos magistrados frente aos políticos (Pederzoli e Guarnieri, 1997; Rossetti, 2000; Sberna e Vannucci, 2013). Especificamente em relação aos promotores, a intenção foi

"[E]vitar a possibilidade que os poderes do Ministério Público pudessem ser usados de forma politicamente discriminatória, como tinha sido anteriormente no período fascista, [por isso] consideraram necessário retirar a tradicional ligação que existia entre promotores hierarquicamente dependentes do ministro da justiça” (Di Federico, 1995, p. 236, tradução nossa).

Um importante instrumento institucional para garantir essa autonomia foi a criação do Alto Conselho da Magistratura, que se consolidou como "um efetivo 'órgão de autogoverno" nos anos 1970 para os 7.000 magistrados italianos (Sberna e Vannucci, 2013, p. 581, tradução nossa). O Conselho é formado por $2 / 3$ de seus membros eleitos pelos próprios juízes e apenas 1/3 pelo parlamento (Nelken, 1996). Mas o Alto Conselho tem papel limitado, já que juízes e promotores são protegidos do controle das instâncias superiores do próprio Poder Judiciário (Guarnieri, 2015). Na prática, isso pode ser observado pelas regras de promoção na carreira dos magistrados, que são típicos instrumentos de incentivo no serviço público para que subordinados observem os desejos da chefia.

“(...) o desempenho no trabalho é avaliado pelo Alto Conselho por meio de uma avaliação 'global' e não é 
segredo que, uma vez que essas avaliações são quase todas invariavelmente positivas, promoções são de fato exclusivamente reguladas por antiguidade. Além disso, uma vez que as promoções não mais dependem da existência de postos vagos nos altos níveis, o magistrado que é promovido obtém seu salário na mais alta escala enquanto exerce sua função anterior: cada membro do Judiciário pode alcançar o mais alto posto, pelo menos do ponto de vista econômico, em vinte e oito anos sem se submeter a nenhuma seleção profissional relevante" (Pederzoli e Guarnieri, 1997, p. 330, tradução nossa).

A consequência é que com a "exceção dos esforços recentes para coordenar a luta contra o crime organizado, cada promotoria é autônoma" (Nelken, 1996, p.100, tradução nossa), o que permite que as preferências pessoais sejam percebidas na atuação dos magistrados em suas atividades 270 de combate ao crime e na condução de investigações (Di Federico, 1995), refletindo em uma atuação menos previsível e uniforme.

Esse modelo incomum em democracias, em que um ator é pouco accountable, poderia ser minimizado por uma baixa discricionariedade. A legislação que prevê que não se pode lançar uma quantidade $X$ de poluentes, para resgatar um exemplo dado por Schoenbroad (1993), é diferente daquela que diz que não se deve lançar uma quantidade excessiva, o que permite interpretação do burocrata.

A ação penal na Itália pode sugerir menor discricionariedade à primeira vista, já que ela é de tipo "legal" e, portanto, compulsória. "Sob esse princípio, é obrigatória a instauração de um processo para todos os delitos sobre os quais existam evidência de culpa do acusado, e o critério de interesse público é irrelevante na tomada de decisão do promotor" (Fionda, 1995, p. 9, tradução nossa). Não caberia 
escolha, como nos modelos de promotoria burocrático e eleitoral: o promotor italiano deveria apresentar necessariamente todas as ações penais, independentemente da gravidade, para um julgamento.

Essa exigência pode ser lida de duas maneiras. Por um lado, seria um instrumento de defesa da própria sociedade, porque não cabe ao promotor isoladamente interromper uma ação por razões que nem sempre são claras. $\mathrm{O}$ que enfraquece esse mecanismo, contudo, é que o juiz e o promotor fazem parte da mesma instituição, diminuindo a possibilidade de checks and balances internos ao sistema. Por outro lado, essa compulsoriedade da ação penal é uma garantia aos próprios promotores contra ingerências políticas, já que nenhum ator externo ao MP pode usar de expedientes para barrar o processo, porque os promotores estão "protegidos de qualquer forma de accountability" (Pederzoli e Guarnieri, 1997, p. 334, tradução nossa).

Essa aparente falta de discricionariedade, contudo, ficou fragilizada pela aprovação, em 1989, de um novo código criminal, em que o poder de dirigir a Polícia na fase de investigação passou a ser responsabilidade dos promotores (Pederzoli e Guarnieri, 2008) ${ }^{13}$. A discricionariedade, na prática, não é mais limitada pelo princípio da legalidade, já que o promotor não espera passivamente ser acionado para iniciar um processo penal e, portanto, apenas aceitar as provas levantadas por outro ator.

\footnotetext{
13 Duas mudanças importantes nessa reforma: o fim do juiz de instrução, em que o magistrado tem um papel mais ativo nas questões criminais, e a consequente substituição do modelo "inquisitorial" pelo "adversarial", em que o juiz é neutro em relação a acusação e defesa (Sberna e Vannucci, 2013; Guarnieri, 2015). Mas o fato de magistrados pertencerem à mesma instituição, contudo, limita a independência do juiz em relação à acusação. Os promotores, segundo Nelken, nunca agiram "simplesmente como uma contraparte oficial do advogado de defesa" (1996, p. 100, tradução nossa).
} 
"Em outras palavras, é perfeitamente legítimo que iniciem ou protagonizem, com grande independência, investigações de qualquer tipo, sobre quaisquer cidadãos, utilizando de diversas forças policiais para verificar se as infrações que eles (mais ou menos justificadas) assumem existir, foram realmente cometidas" (Di Federico, 1995, p. 237, tradução nossa).

O paradoxo aqui, continua o autor, é que

“[...] a preservação da irrealizável previsão constitucional das iniciativas criminais compulsórias, longe de proteger a igualdade dos cidadãos frente à lei, frequentemente promove tratamentos desiguais por conta das diferentes orientações dos vários promotores" (Di Federico, 1995, p. 239, tradução nossa).

Além disso, dada a amplitude de matérias que podem 272 ser tratadas por meio de uma ação penal, "[...] junto com as criativas interpretações de muitos membros do Judiciário permite a eles motivos suficientes para iniciar investigações em grandes áreas de atividades administrativas, políticas e mesmo econômicas" (Pederzoli e Guarnieri, 1997, p. 334, tradução nossa). A lista de assuntos em que os promotores podem se envolver é longa: vai desde segurança no trabalho até questões de poluição ambiental, passando por evasão de impostos, fraudes bancárias e corrupção. Em certo sentido, o promotor pode lançar mão da compulsoriedade quando lhe convém, definindo e implementando, muitas vezes baseado em critérios pessoais, a política criminal do país (Di Federico, 1995).

Dessa forma, todas as etapas do processo criminal investigação, acusação e julgamento -, que podem englobar uma gama significativa de assuntos, convergiram para as mãos de uma única instituição: o Poder Judiciário italiano. Se um modelo como esse, por um lado, pode 
diminuir os custos de transação gerados quando é preciso cumprir uma série de etapas e envolver instituições diversas, por outro, não há uma clara divisão de tarefas que poderia gerar um sistema de checks and balances interno ao sistema de justiça, aumentando a chance de correção de eventuais falhas ao longo do processo. Na Itália, a acusação tem significativa vantagem em relação à defesa em um processo criminal.

Em síntese, o MP italiano é um órgão de Estado autônomo em relação ao governo e aos eleitores e parte integrante do Poder Judiciário. Seus membros não são controlados por um poder hierárquico, e a ação penal não se restringe aos crimes comuns. Além disso, exercem controle sobre a Polícia durante as investigações, o que reforça que há espaço para discricionariedade desses magistrados. No modelo italiano, os órgãos de investigação, acusação e julgamento se confundem, em um modelo institucional em que altas doses de discricionariedade e autonomia não são limitadas por mecanismos de accountability externo. $\mathrm{O}$ modelo independente é um desenho institucional incomum à democracia.

Foi essa moldura institucional que garantiu que os magistrados italianos atuassem com ampla independência na Operação Mãos Limpas, permitindo a adoção de uma estratégia baseada em dois pontos: delações dos investigados e busca por apoio da opinião pública.

O primeiro ponto foi perseguido por meio de delações incentivadas obtidas graças a acordos de leniência, acertados com vistas a evitar "detenções antes dos julgamentos" (Guarnieri, 2015, p. 125, tradução nossa). "Tão logo presos os primeiros políticos e empresários -deliberadamente colocados pelos juízes milaneses em uma situação de tipo 'dilema do prisioneiro' - começaram a colaborar com os juízes, todo o mecanismo foi posto em movimento" (Sberna e Vannucci, 2013, p. 576, tradução nossa). Na busca de obter 
vantagens para si, como não ir preso antes do julgamento, o investigado apontava outros nomes, o que garantia a sequência das investigações.

Outra parte da estratégia era obter o apoio da opinião pública utilizando a imprensa, especialmente a controlada de forma privada e que competia com os tradicionais veículos de comunicação públicos da Itália (Giglioli, 1996). Os magistrados italianos

“[...] algumas vezes fizeram uso estratégico de suas habilidades para tornar públicas informações sobre acusações criminais, às vezes (ilegalmente) vazando a história para um jornalista aliado. Essa oferta não apenas era uma oportunidade para aumentar o prestígio, mas também possíveis vantagens para as investigações que eles estavam conduzindo" (Nelken, 1996, p. 101, tradução nossa).

274 De certa forma, os "jornalistas eram 'usados' pelos magistrados para levantar apoio para sua investigação" (Sberna e Vannucci, 2013, p. 576-577, tradução nossa). O que no início era uma competição entre políticos e magistrados pelo apoio popular, transferiu-se para o campo da luta partidária propriamente dita, com vários promotores disputando eleições e, inclusive, fundando um novo partido político (Guarnieri, 2015) ${ }^{14}$.

\section{0 caso brasileiro}

A partir da Constituição de 1988, que assim como a Constituição italiana de 1948 buscava responder ao período não democrático anterior, o modelo burocrático de MP no Brasil foi desfeito. No lugar de um órgão ligado ao governo, e portanto accountable e orientado por políticos, os promotores brasileiros, recebendo as mesmas garantias dos juízes, passam a

14 Di Pietro fundou o partido Italia Dei Valori (Guranieri, 2015). 
ser significativamente autônomos em relação à accountability de outras instituições públicas ${ }^{15}$ e dos eleitores, com exceção do Poder Judiciário. Um membro do MP agir no sentido desejado pelos cidadãos é uma coincidência, mas não consequência de estímulos gerados por eleições ou por instrumentos cotidianos de controle por parte do governo ou de políticos.

Assim como na Itália, essa autonomia não se refere somente aos atores externos, mas também à própria estrutura interna. O procurador-geral, supostamente o chefe do MP, possui poucos instrumentos institucionais para incentivar certos comportamentos e desestimular outros ${ }^{16}$. Além da estabilidade no emprego dos promotores, dois outros princípios institucionais limitam o poder do procurador-geral: o primeiro é a promoção por antiguidade, permitindo que mesmo os promotores não alinhados, menos combativos e com um estilo mais "burocrático" tenham progressão na carreira ${ }^{17}$. O segundo instrumento é o princípio do "promotor natural", que impede que o procurador-geral ou os órgãos colegiados da instituição selecionem os promotores de suas preferências para casos específicos, já que um réu somente pode ser processado por aquele previamente designado da comarca.

Uma maneira de contornar essas limitações é a criação, por parte do procurador-geral da república, assim como dos procuradores-gerais de justiça dos estados, de forças-tarefas ou grupos especiais para o combate a crimes mais

\footnotetext{
${ }^{15}$ Em 2003 foi criado o Conselho Nacional do MP. Embora essa iniciativa pudesse sugerir uma maior accountability sobre os MP estaduais e o Federal, na verdade, seus membros são majoritariamente promotores. Portanto, o critério de que a accountability é exercida por um ator externo não é totalmente atendido.

16 Referência a instrumentos previstos em legislação, sem levar em conta aqueles de tipo mais simbólicos, na "zona nebulosa das instituições" (Arrow, 1985, p. 50, tradução nossa), estudados pela sociologia das profissões ou pelos sociólogos neoinstitucionalistas, como laços de amizade, posicionamentos político-partidários etc. (Peters, 2012).
}

17 Segundo Silva (2001), há os promotores "de fatos" e "de gabinete". 
complexos, o que foi feito na Operação Lava Jato. Nesse sentido, a chefia da instituição pode escolher os promotores mais afinados ou incentivar um alinhamento. Embora essa iniciativa permita que o procurador-geral crie alguma marca frente ao cenário monocrático que é a instituição, por outro, pode ser uma maneira de driblar o princípio do promotor natural, um dos poucos instrumentos de limitação ao poder dos promotores e de defesa do cidadão.

Autonomia, contudo, pode ser menos incomum ao modelo democrático quando acompanhada de baixa discricionariedade. Uma instituição autônoma que simplesmente aplica a lei é diferente de outra que a interpreta. "Uma coisa [...] é colocar as políticas públicas para além do controle democrático de acordo com as relativamente fixas cláusulas da constituição e outra completamente diferente é colocá-las nas mãos de uma agência de governo com um poder discricionário" (Shapiro, 1997, p. 289, tradução nossa). Em 276 relação à ação penal, monopólio do MP e sua mais tradicional atribuição, os constituintes, assim como seus pares italianos, optaram por um modelo de menor discricionariedade, pelo menos em tese ${ }^{18}$. Diferentemente do adotado pelo desenho burocrático e eleitoral de promotoria, os promotores brasileiros são obrigados pelo "princípio da legalidade" a levar todos os casos encaminhados pela Polícia ao Poder Judiciário. Além de diminuir a discricionariedade, diferentemente do sistema de justiça italiano, criou-se uma divisão de tarefas, o que permite à justiça ter um mecanismo de checks and balances interno ao próprio sistema: o policial investiga, o promotor acusa e o juiz decide sobre o caso. Por outro lado, o princípio da legalidade também cumpre o papel de proteger o promotor contra ingerências externas, já que o

18 Existem outros instrumentos nas mãos dos promotores brasileiros, mas que não foram centrais na Operação Lava Jato: a ação civil pública, o inquérito civil e o termo de ajuste de conduta (TAC). Além da discricionariedade, o inquérito e o TAC não precisam nem passar por um juiz (Arantes, 1999). 
integrante do MP poderá alegar que não cabe a ele decidir se um caso contra um político, por exemplo, merece ou não ser levado à justiça.

No modelo criado pelos constituintes brasileiros, portanto, o MP se aproximava do modelo italiano pela i) autonomia da instituição em relação aos atores externos; ii) proteção dos promotores contra ingerências dos supostos chefes do MP e iii) adoção do princípio da legalidade em relação à ação penal, que limita a discricionariedade do promotor. As diferenças entre o sistema de justiça de primeira instância dos dois países, contudo, eram que iv) juízes e promotores não fazem parte da mesma instituição e v) promotores não são responsáveis por conduzirem investigações criminais, ambas iniciativas que limitam poder e aumentam as chances de correção de erros e arbitrariedades da própria justiça. A Constituição brasileira de 1988 garantiu autonomia aos promotores, mas buscou gerar uma espécie de checks and balances interno ao sistema. Nesse modelo, os custos de transação são mais altos do que na Itália, o que poderia dificultar o combate à corrupção, mas geraria maior possibilidade de corrigir eventuais erros durante o processo. $\mathrm{O}$ modelo italiano, por sua vez, facilita a atuação contra a corrupção, diminuindo os custos de transação, porque todas as etapas - investigação, acusação e julgamento - são concentradas na mesma instituição. Por outro lado, isso pode prejudicar o direito à defesa, além de aumentar a possibilidade do erro pela falta de controles internos.

O modelo institucional da Constituição de 1988, contudo, é diverso em alguns aspectos daquele em que se dá a Operação Lava Jato em primeira instância. As diferenças entre os ministérios públicos brasileiro e italiano - pontos IV e V - foram minimizadas por aparentes acordos tácitos entre os atores da Lava Jato e por mudanças na legislação patrocinadas por políticos durante os governos do Partido dos Trabalhadores (2003-2016) e pelo STF, diminuindo os 
custos de transação ao combate à corrupção também no Brasil. Houve uma migração, não necessariamente permanente, do modelo autônomo de promotoria brasileira para algo mais próximo do modelo independente encontrado na Itália. Os instrumentos de checks and balances internos ao sistema de justiça, entretanto, tornaram-se mais frágeis.

Essas mudanças identificadas no Brasil devem-se, pelo menos em parte, aos três "deslocamentos" experimentados pelo sistema de justiça brasileiro no que diz respeito ao combate à corrupção nos últimos anos (Arantes, 2014). Um dos deslocamentos foi a passagem da esfera civil para a criminal; os promotores, que antes baseavam sua atuação no combate à improbidade administrativa por meio da ação civil, passaram a adotar a ação penal como o instrumento de luta contra a corrupção. Arantes aponta que o uso da ação civil nas primeiras experiências de combate à corrupção posterior a 1988 se impunha porque, diferentemente da ação penal, os 278 promotores não precisavam da autorização de juízes e da dependência da Polícia para conduzir investigações, graças à previsão constitucional de que o inquérito civil é monopólio do MP. Assim, os promotores contornavam a necessidade de uma "triangulação entre os principais atores do sistema" (Arantes, 2014, p. 6) e as dificuldades relacionadas a articular instituições diversas, podendo conduzir suas próprias investigações e atuando com mais liberdade. Outro motivo é que com a chamada "Lei da delação Premiada" (Lei 12.850/13), os promotores passaram a poder negociar, sem a interferência direta de um juiz, penas menores para um acusado em troca de denúncias de supostos comparsas, nivelando com matérias cíveis a discricionariedade do Ministério Público para assuntos criminais (Avritzer e Marona, 2017; Kerche e Marona, 2018).

Para completar esse deslocamento, o STF em 2015 autorizou de forma definitiva que o MP conduza inquéritos penais, contrariando o desejo dos constituintes, mas 
tornando legal prática já exercida por muitos promotores (Kerche, 2014). Ou seja, no lugar de aguardar o resultado das investigações da Polícia para, obrigatoriamente, apresentar o caso ao Poder Judiciário, diminuindo em tese a discricionariedade, os promotores podem atuar de maneira pró-ativa e com maior independência da Polícia, um dos vértices do triângulo da justiça.

Os outros deslocamentos foram a passagem de um modelo baseado em "competição" e "sobreposição" entre as instituições do sistema de justiça para um modelo "cooperativo", e o protagonismo dos atores federais e não mais estaduais no combate à corrupção. Em ambos os casos, "não por qualquer reforma na legislação, mas por uma maior articulação e sintonia de propósitos entre as três instituições diretamente envolvidas com os processos judiciais, pelo menos no plano federal" (Arantes, 2014, p. 9).

A colaboração da Polícia Federal com os promotores na primeira instância da Lava Jato, o que não significa que seja harmoniosa em todos os momentos ${ }^{19}$, é facilmente identificável e celebrada ${ }^{20}$. A parceria do juiz é menos evidente; alguns indícios, contudo, reforçam a hipótese de que ela existe. Primeiro, como aponta Arantes (2014), a mudança da estratégia da ação civil para a penal somente foi possível porque os atores passaram a trabalhar de forma cooperada e isso não seria plenamente possível se o Poder Judiciário também não colaborasse. O segundo indício são as críticas

19 Disponível em: <https://www.nexojornal.com.br/expresso/2017/04/18/ Pol\%C3\%ADcia-Federal-e-Minist\%C3\%A9rio-P\%C3\%BAblico-travam-disputavelada-na-Lava-Jato.-Qual-o-papel-de-cada-um>. Acesso em: 04 set. 2018.

20 "O Ministério Público Federal e a Polícia Federal trabalharam de modo integrado. Ambos foram e são essenciais para o sucesso do caso. As medidas solicitadas à Justiça e operacionalizadas pela Polícia foram feitas com o aval e concordância do Ministério Público, e as atividades dos procuradores da República contaram com a concordância e o apoio da PF. O caso é um exemplo de união de esforços para lutar contra a corrupção, a impunidade e o crime organizado". Disponível em: $<$ http://lavajato.mpf.mp.br/atuacao-na-1a-instancia/investigacao/fluxo-da-investigacao>. Acesso em: 31 mar. 2017. 
recorrentes de que a defesa estaria em desvantagem em relação à acusação na Lava Jato e que o MP estaria sendo privilegiado pelo juiz de primeira instância ${ }^{21}$. Terceiro, além das medidas solicitadas pela Polícia Federal e MP autorizadas pelo juiz na fase de investigação, há mais chance de um nome acusado pelo MP ser condenado do que absolvido. Dos 117 réus, 92 (78,6\%) foram considerados culpados em pelo menos uma das acusações ${ }^{22}$.

Essas mudanças minimizam as diferenças entre o sistema italiano e brasileiro. Além do baixo grau da accountability do MP, da falta de hierarquia e do princípio da legalidade, temos um sistema de justiça na primeira instância da Lava Jato em que as fronteiras institucionais dos atores envolvidos não são mais tão demarcadas e a possiblidade do MP trabalhar em conjunto com a Polícia ou investigar por moto-próprio foram reforçadas. Na Operação Lava Jato, pelo menos em sua instância inicial, os custos de transação de uma ação penal para o combate à corrupção diminuíram por conta de uma espécie de fragilização das fronteiras institucionais entre Poder Judiciário, MP e Polícia. Se o MP na Operação Lava Jato e o MP italiano na Operação Mãos Limpas não são animais da mesma espécie, talvez por conta do foro privilegiado e pelo protagonismo do procurador-geral por meio de forças-tarefas no caso brasileiro, são pelo menos do mesmo gênero, usando conceitos da biologia.

Essa moldura institucional, que aproximou o Brasil do modelo italiano e é diversa daquela aprovada pelos

\footnotetext{
${ }^{21}$ Segundo Toron (2016), o direito à defesa foi prejudicado durante a Lava Jato pela "escassez de tempo para a apresentação das defesas, denúncias fatiadas com o comprometimento da compreensão da narrativa fática e dificuldades de se conversar com os presos por meio de interfone no parlatório da cadeia da Polícia Federal" (p. 1). E, frente às reclamações, somente "havia ouvidos para a importância da acusação e a beleza da eficiente atuação do juiz Moro" (p. 8).

22 Disponível em: <http://lavajato.mpf.mp.br/atuacao-na-1a-instancia/denuncias-do-mpf $>$. Acesso em: 09 mar. 2017. Até o término desta pesquisa, foram 118 acusados, mas um faleceu durante o processo e não foi julgado.
} 
constituintes brasileiros, facilitou que os atores do sistema de justiça envolvidos na Operação Lava Jato, especialmente na primeira instância, empregassem estratégias similares às dos magistrados da Operação Mãos Limpas. Por um lado, o abastecimento de veículos de imprensa com informações foi largamente utilizado, havendo "uma interação bastante próxima das instituições de justiça com as mídias e a opinião pública, em uma clara estratégia de legitimação dos agentes judiciais" (Almeida, 2016, p. 76). Por outro, as prisões, mesmo antes dos julgamentos e das condenações, serviram como um incentivo para as chamadas delações premiadas e pela inclusão de novos suspeitos, num sistema que se autoalimenta ${ }^{23}$.

\section{Considerações Finais}

Os números superlativos de políticos e empresários investigados e presos na Operação Mãos Limpas na Itália não escondem, contudo, uma aparente unanimidade de que os magistrados foram incapazes de acabar com a corrupção na Itália e que o país ainda é um dos que mais padecem desse mal na Europa (Fukuyama, 2014). Como definiu Vannucci, em entrevista à BBC, “A Mãos Limpas pode ser considerada uma conquista incrível em curto prazo, mas um fracasso em longo"24. O problema é que as reformas institucionais necessárias não foram realizadas (Sberna e Vannucci, 2013), modificando pouco as bases que tornaram possível a ocorrência de ilegalidades. Além das consequências políticas,

${ }^{23}$ O juiz Sérgio Moro, um dos protagonistas da Lava Jato, reconhece que esta era a estratégia italiana: "A estratégia de ação adotada pelos magistrados incentivava os investigados a colaborar com a justiça: A estratégia de investigação adotada desde o início do inquérito submetia os suspeitos à pressão de tomar decisão quanto a confessar, espalhando a suspeita de que outros já teriam confessado e levantando a perspectiva de permanência na prisão pelo menos pelo período da custódia preventiva no caso da manutenção do silêncio ou, vice-versa, de soltura imediata no caso de uma confissão (...)" (Moro, 2004, p. 58).

24 Disponível em: <http://www.bbc.com/portuguese/noticias/2016/03/160316_ lavajato_dois_anos_entrevista_lab>. Acesso em: 14 fev. 2017. 
com o desmonte do sistema partidário e a eleição do controverso Berlusconi, houve uma espécie de frustração por parte da sociedade, já que o número de condenações teria sido proporcionalmente baixo - dos 3.200 réus, 2.200 não foram condenados. E o resultado é que a corrupção deixou de ser importante no debate eleitoral: somente $0,2 \%$ dos eleitores em 2008 consideravam o tema como a pauta prioritária do governo (Sberna e Vannucci, 2013).

Em relação ao Brasil, seria prematura uma conclusão definitiva sobre a Operação Lava Jato de maneira geral e sobre seu braço na primeira instância de maneira específica. Não se sabe, por exemplo, se algum dos protagonistas tentará a carreira política, como foi o caso entre os magistrados italianos. Também não é ainda possível afirmar se esse modelo será reproduzido em outras comarcas e para diferentes casos. Os resultados da movimentação dos políticos no calor dos acontecimentos para limitar a judicialização 282 do combate à corrupção e se proteger de prisões decretadas pelo Judiciário, semelhante ao que ocorreu na Itália pós-Mãos Limpas, têm resultados ainda incertos. Mas uma coisa parece ser inequívoca: o combate à corrupção feito pelo sistema de justiça na Operação Lava Jato, particularmente na primeira instância, deixará marcas no sistema político em nível nacional e seus reflexos serão sentidos ainda por muito tempo.

\section{Fábio Kerche}

é doutor em Ciência Política pela USP e pesquisador titular da Fundação Casa de Rui Barbosa, Rio de Janeiro. Este artigo foi escrito enquanto o autor estava como research fellow no Center for Latin American and Latino Studies da American University, Washington, DC. Uma versão preliminar foi apresentada na MACLAS 2017 (Middle Atlantic Council of Latin American Studies) com o título "Brazilian Prosecutor's office and the 'italianization' of the fight against corruption". 
Agradeço a leitura e sugestões de Matthew Taylor, Gilberto Rodrigues, Márcio Cunha Filho, Celina de Souza, Rafael Ioris, Sérgio Ferraz e aos pareceristas anônimos desta revista. Desnecessário dizer que os eventuais erros são de minha responsabilidade.

\section{Bibliografia}

AAKEN, Anne van; FELD, Lars P.; VOIGT, Stefan. 2010. Do independent prosecutors deter political corruption? An empirical evaluation across seventy-eight countries. American Law and Economic Review, v. 12, n. 1, pp. 204-244.

ALMEIDA, Frederico de. 2016. Justiça, combate à corrupção e política: uma análise a partir da operação Lava Jato. Revista Pensata, v. 5, n. 2, pp. 69-82.

ARANTES, Rogério Bastos. 1999. Direito e política: o Ministério Público e a defesa dos direitos coletivos. Rev. Brasileira de Ciências Sociais, v. 14, n. 39, pp. 83-102.

2002. Ministério Público e política no Brasil. São Paulo: Fapesp. 2014. Maluf x Genoino: (des) caminhos da Justiça no combate à corrupção no Brasil. Paper apresentado no IX Encontro da Associação Brasileira de Ciência Política, Brasília, 4 a 7 de agosto.

ARROW, Kenneth J. 1985. The Economics of agency. In: PRATT, John W.; ZECKHOUSER, Richard. J. (eds.). Principals and agents: The structure of business. Boston: Harvard Business School, pp.37-51.

AVRITZER, Leonardo; MARONA, Marjorie. 2017. A tensão entre soberania e instituições de controle na democracia brasileira. Dados, v. 60, n. 2, pp. 359-393.

BOVENS, Mark; GOODIN, Robert E.; SCHILLEMANS, Thomas. (ed.). 2014. The Oxford handbook of public accountability. Oxford: Oxford University Press.

BURBANK, Stephen. B.; FRIEDMAN, Barry. (eds.). 2002. Judicial independence and the crossroads: an interdisciplinary approach. Thousand Oaks: Sage Publications.

DAHL, Robert. A. 1982. Dilemmas of pluralist democracy: autonomy vs. control. New Haven: Yale University Press.

DI FEDERICO, Giuseppe. 1995. Italy: a peculiar case. In: TATE, C. Neal.; VALLINDER, Torbjörn. (eds.). The global expansion of judicial power. Nova York: NYU Press, pp. 233-241. 
FIONDA, Julia. 1995. Public prosecutors and discretion: a comparative study. Oxford: Clarendon Press.

FUKUYAMA, Francis. 2014. Political order and political decay. Nova York: Farrar, Straus and Giroux.

GIGLIOLI, Pier Paolo. 1996. Political corruption and the media: the Tangentopoli affair. International Social Science Journal, v. 48, Issue 149, pp. 305-438.

GINSBORG, Paul. 1996. Explaining Italy's crisis. In: GUNDLE, Stephen; PARKER, Simon. (eds.) The new Italian republic: from the fall of the Berlin wall to Berlusconi. Londres: Routledge, pp. 19-39.

GUARNIERI, Carlo. 1995. Judicial independence and policy-making in Italy. In: TATE, C. Neal; VALLINDER, Torbjörn. (eds.). The Global expansion of judicial power. Londres: NYU Press, pp. 243-259.

2015. The courts. In: JONES, Erik; PASQUINO, Gianfranco. (eds.). The Oxford handbook of Italian politics. Oxford: Oxford University Press, pp.120-132.

GRUBER, Judith E. 1987. Controlling bureaucracies: dilemmas in democratic governance. Berkeley, Los Angeles, Londres: University of California Press. JOHNSON, David T. 2012. Japan's prosecution system. In: TONRY, Michael. (ed.). Prosecutors and politics: a comparative perspective. Chicago: The University Chicago Press, pp. 35-74.

KERCHE, Fábio; MARONA, Marjorie. 2018. O Ministério Público na Operação Lava Jato: como eles chegaram até aqui? In: KERCHE, Fábio, FERES Jr., João. (coords.) Operação Lava Jato e a democracia brasileira. São Paulo: Editora Contracorrente, pp. 69-100.

KERCHE, Fábio. 2005. Agências responsáveis pela ação penal: um estudo comparativo. Revista Brasileira de Ciências Criminais, v. 54, pp. 127-152. 2009. Virtude e limites: autonomia e atribuições do Ministério Público no Brasil. São Paulo: Edusp. 2014. O Ministério Público no Brasil: relevância, características e uma agenda para o futuro. Revista USP, n. 101, pp. 114-120.

JOHNSON, Charles A..; BRICKMAN, Danette. 2001. Independent counsel: the law and the investigations. Washington: CQ Press.

LOTTA, Gabriela; SANTIAGO, Ariadne. 2017. Autonomia e discricionariedade: matizando conceitos-chave para o estudo da burocracia. BIB, n. 83, pp. 21-42.

MORO, Sérgio Fernando. 2004. Considerações sobre a operação mani pulite. $R$. CEJ, n. 26, pp. 56-62.

NELKEN, David. 1996. The judges and political corruption in Italy. Journal of Law and Society, v. 23, n. 1, pp. 95-112. 
O’DONNELL, Guillermo. 1998. Accountability horizontal e novas poliarquias. Lua Nova, n. 44, pp.27-54.

PEDERZOLI, Patrizia; GUARNIERI, Carlo. 1997. The judicialization of politics, Italian style. Journal of Modern Italian Studies, v. 2, n. 3, pp. 321-336.

PEDERZOLI, Patrizia; ANIA, G. 2004. The reform of the judiciary. Italian Politics, Vol. 20, pp. 153-171.

PETERS, Guy B. 2012. Institutional theory in political science. Nova York: Continuum.

PRATT, John W.; ZECKHAUSER, Richard Jay. (ed.). 1984. Principals and agents: the structure of business. Boston: Harvard Business School Press.

PRZEWORSKI, Adam. 1998a. Sobre o desenho institucional do Estado: Uma perspectiva agent $x$ principal. In: PEREIRA, Luiz Carlos Bresser; SPINK, Peter. (orgs.). Reforma do Estado e administração pública gerencial. Rio de Janeiro; FGV, pp. 39-75.

1998b. The State and the citizen. Paper preparado para o seminário Society and Reform of the State, Conselho da Reforma do Estado, São Paulo, 26 a 28 de março.

ROSSETTI, Carlo. 2000. The prosecution of political corruption: France,

Italy and the USA - A comparative view. Innovation, v. 13, n. 2, pp. 168-181.

SBERNA, Salvatore; VANNUCCI, Alberto. 2013. 'It's the politics, stupid!': the politicization of anti-corruption in Italy". Crime Law Soc. Change, v. 60, pp. 565-593.

SCHOENBROAD, David S. 1993. Power without responsibility: how congress abuses the people through delegation. New Heaven: Yale University Press.

SHAPIRO, Martin. 1997. The problems of independent agencies in the United States and the European Union. Journal of European Public Policy, v. 4, n. 2, pp. 276-291. 2013. Judicial independence: New challenges in established nations. Indiana Journal of Global Legal Studies, v. 20, n. 1, pp. 253-277.

SILVA, Cátia Aida. 2001. Promotores de justiça e novas formas de atuação em defesa de interesses sociais e coletivos. Revista Brasileira de Ciências Sociais, vol. 16, n. 45, pp. 127-144.

TAVARES FILHO, Newton. 2016. Foro privilegiado: pontos positivos e negativos. Brasília, DF: Câmara dos Deputados. Disponível em: $<$ http://www2.camara.leg.br/documentos-e-pesquisa/publicacoes/ 
estnottec/areas-da-conle/tema6/2016_10290_foro-privilegiado-pontospositivos-e-negativos>. Acesso em: 06 jan. 2017.

TERQUEM, F. 1998. Le coup D'État judiciaire. Paris: Éditions Ramsay.

TONRY, Michael. 2012. Prosecutors and politics in comparative perspective. In: Prosecutors and politics: a comparative perspective. Chicago: The University Chicago Press, pp. 1-33.

TORON, Alberto Zacharias. 2016. O direito de defesa na Lava Jato. Revista Brasileira de Ciências Criminais. v. 122, Disponível em: <http:// www.mpsp.mp.br/portal/page/portal/documentacao_e_divulgacao/ doc_biblioteca/bibli_servicos_produtos/bibli_boletim/bibli_ bol_2006/122.01.PDF>. Acesso em: 31 mar. 2017.

WEBER, Max. 1972. Ciência e política: duas vocações. São Paulo, Cultrix.

WEST, William. F. 1995. Controlling the bureaucracy: institutional constraints in theory and practice. Londres: Rotledge. 


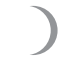

\section{MINISTÉRIO PÚBLICO, LAVA JATO E MÃOS LIMPAS: UMA ABORDAGEM INSTITUCIONAL}

\section{FÁBIO KERCHE}

Resumo: A operação de combate à corrupção na Itália no início dos anos 90 do século XX, conhecida como Mãos Limpas, foi fonte de inspiração para a $1^{\circ}$ instância do sistema de justiça brasileiro na condução da Operação Lava Jato. Isso se deu não somente do ponto de vista da estratégia, baseada em delações dos acusados e disputa pela opinião pública, mas do ponto de vista institucional: houve uma aproximação da polícia, promotores e o juiz encarregado do caso em que as fronteiras entre as instituições ficaram menos claras. Diferentemente do previsto pelos constituintes brasileiros, a divisão de tarefas entre os atores do sistema de justiça foi atenuada, facilitando o combate à corrupção, mas enfraquecendo garantias dos acusados e colocando em risco o sistema político.

Palavras-chave: Democracia; Accountability; Ministério Público; Corrupção.

\section{BRAZILIAN PROSECUTOR'S OFFICE, CAR WASH AND CLEAN HANDS: AN INSTITUTIONAL APPROACH}

Abstract: The anti-corruption operation in Italy in the early 1990s, known as Clean Hands, was a source of inspiration for the trial court of the Brazilian judicial system in conducting the Operation Car Wash. This was not only from the point of view of strategy, based on the defendants' accusations and the dispute for public opinion, but from the institutional point of view as well: the limits between the police, the prosecutors, and the judge in charge of the case, have been blurred; the institutional boundaries became less evident as in comparison with Italy. Different from the Brazilian framers' decision, the division of labor among the actors of the 
Brazilian judicial system has been attenuated, facilitating the fight against corruption, but weakening the guarantees for the accused, and jeopardizing the political system.

Keywords: Democracy; Accountability; Brazilian Prosecutor's Office; Corruption.

Recebido: $10 / 04 / 18 \quad$ Aprovado: $05 / 11 / 18$ 